\title{
THE OPERATING LOAD OF A DISINTEGRATION MACHINE
}

\author{
Juraj Beniak*, Peter Križan, Miloš Matúš, Monika KováČová \\ Faculty of Mechanical Engineering, Slovak University of Technology in Bratislava \\ * corresponding author: juraj.beniak@stuba.sk
}

\begin{abstract}
The process of disintegration is affected by a large number of operating and design parameters which have not previously been described in detail. This paper discusses the effect of the disintegrative surface area on the size of the operational load of a disintegration machine. This parameter affects the operational power of the device. The paper explains the experimental process, and describes and evaluates the measured data with mathematical functions that describe the relation of the operational power of the devices to a selected parameter.
\end{abstract}

KEYWORDS: Disintegration, shredding, cutting wedge, torque calculation.

\section{Definition of A Disintegrative SURFACE}

It is important to prepare biomass really well for its intended future use $[1,2]$. Several papers have been written on the parameters of disintegration machines. The significance of the monitored parameters that influence the torque moment needed to disintegrate material samples has been investigated. This paper discusses experiments that have been carried out to confirm the mathematical relations (1) for calculating the disintegrative force $[3,4]$, and to determine the mathematical expressions for significant influencing factors such as the area of the sample surface $S$ and the cutting-edge side rake.

Various experiments have shown the significance of four known factors, the most significant being the area of the cross-sectional surface $S$ of the sample (the cross-section that has to be break down by the disintegrative wedge).

Before measuring this parameter, it is necessary to define the area of the cross-section of the sample that has to be broken down by the disintegrative wedge in the disintegration process. Various papers on this topic suggest that area $S$ is calculated by multiplying disintegration wedge width $b$ by wedge height $h$. When this disintegrative process was analyzed in greater detail, it was found that the theory of a constant wedge surface $S$ is not correct. The real area of the cross-section surface that must be broken down by the tool wedge is defined by adding the surface areas that arise after disintegrating the material sample.

Therefore

$$
S_{m}=2 S_{1}+S_{2}
$$

where $S_{1}=h h_{m}$ is the area defined by the side of the wedge and $S_{2}=b h_{m}$ is the area defined by the face of the wedge (Fig. 1). Then

$$
S_{m}=2 h h_{m}+b h_{m}
$$

and, after simplification,

$$
S_{m}=h_{m}(2 h+b),
$$

where $S_{m}$ is the material cross-section area that must be broken down by the disintegrative wedge $\left(\mathrm{mm}^{2}\right)$, $h_{m}$ is the material thickness $(\mathrm{mm}), h$ is the wedge height $(\mathrm{mm})$, and $b$ is the wedge width $(\mathrm{mm})$.

This formula is relevant provided that the sample material width $H$ is greater than the wedge height $h$. If the material sample width $H$ is smaller than the wedge height $h$, then the following is valid:

$$
S_{m}=2 h_{1} h_{m}
$$

where $h_{1}$ is the width of the material sample $\left(h_{1}<h\right)$.

\section{EXPERIMENT FOR DETERMINING THE INFLUENCE OF THE DISINTEGRATIVE SURFACE AREA}

In order to define the relation between the measured data (torque moment $M_{k}$ ) and the section area of a cut in the disintegrative material, experiments were performed with the surface area of the cut as the only factor that was changed. The experiment was performed with five different material samples of varying cross-sectional area. Only the thickness of the sample material $h_{m}$ was varied.

Two relations were revealed. Firstly, the relation of the torque to the area of the cross-section $S$ of the sample materials, and, secondly, the relation of the torque to the thickness $h_{m}$ of the material sample. The width of the sample was kept constant at $30 \mathrm{~mm}$, so that the material was subjected to the whole surface of the wedge while also overhanging the wedge in the outward direction.

The following sample thicknesses were used: 7,10 , 12,15 , and $18 \mathrm{~mm}$, which are the material sizes used for this kind of machine.

Measurements were made with Wedge 2, using the same principles as for the previous experiments. This 


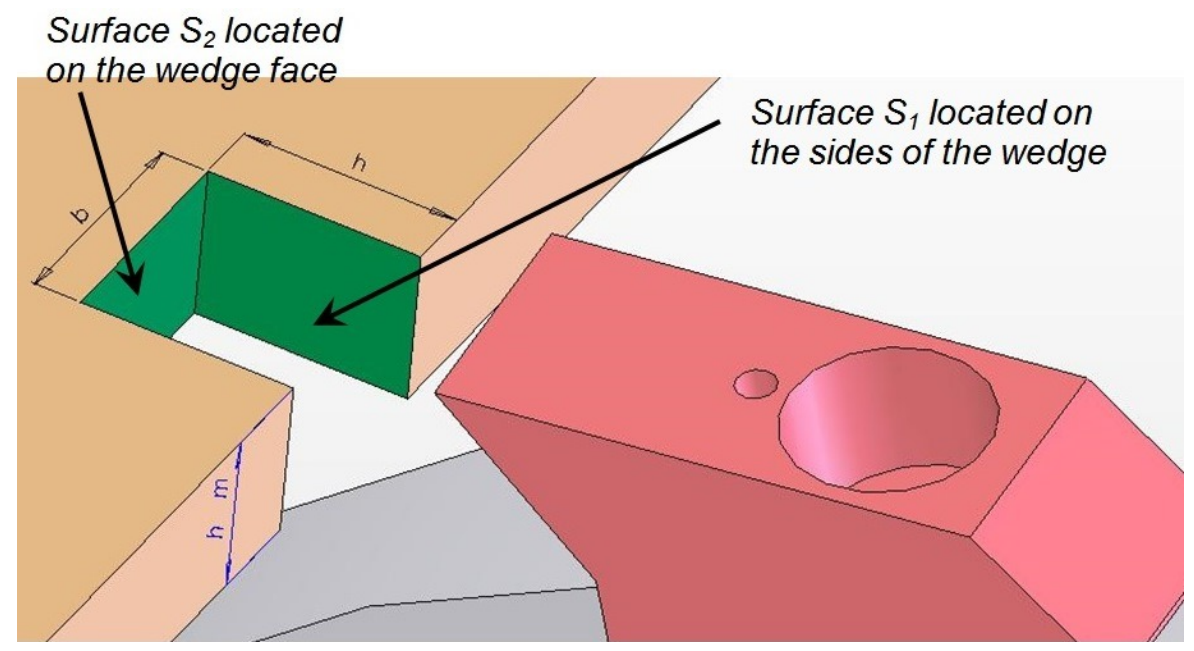

FIGURE 1. Illustration of surfaces used for calculating the disintegrative force.

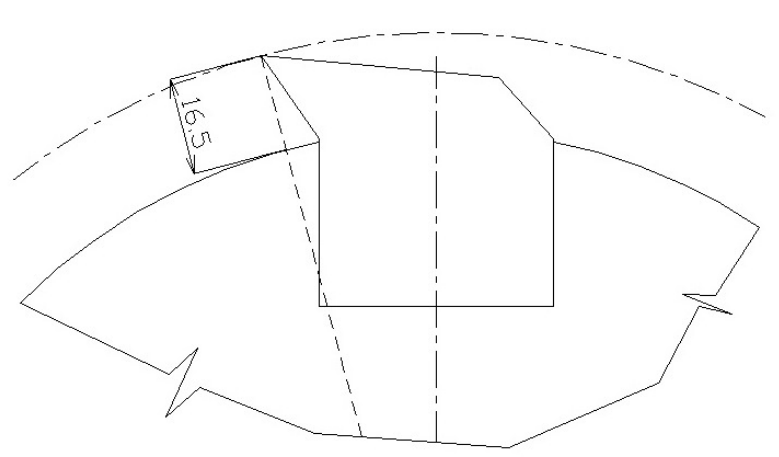

Figure 2. Height of wedge $h=16.5 \mathrm{~mm}$.

wedge was used on the assumption that the measured torque values would be in the measurement range including thicknesses of $18 \mathrm{~mm}$, while Wedges 3 and 4 would result in measured values outside the measurement range. This assumption was based on previous measurements.

For each series of samples, 10 measurements were repeated, for 5 types (levels) of samples, resulting in a total of 50 measurements.

The surface area of the disintegrative cross-section is calculated on the basis of the thickness of the sample, but not on the basis of the whole width, since one portion, beneath the wedge, has already been disintegrated. The value was a maximum of $16.5 \mathrm{~mm}$ (Fig. 2). So the surface area of the material cross-section that has been disintegrated is described by the relation $S_{m}=h_{m}(2 h+b)$.

\section{EXPERIMENTAL EVALUATION}

For the measured values and their corresponding uncertainty, see Tab. 1 (the total uncertainty is equal to the uncertainty evaluated by the A type method), we can write $\overline{M_{k 1}}=(166.7 \pm 21) \mathrm{Nm}$, where the value following the \pm sign represents the expanded uncertainty $U=k u_{C}$, at which uncertainty $U$ is determined from the total (combined) standard uncertainty

\begin{tabular}{cccccc}
\hline Exp. & $\begin{array}{c}h_{m} \\
(\mathrm{~mm})\end{array}$ & $\begin{array}{c}S_{m} \\
\left(\mathrm{~mm}^{2}\right)\end{array}$ & $\begin{array}{c}\overline{M_{k}} \\
(\mathrm{~N} \mathrm{~m})\end{array}$ & $\begin{array}{c}s\left(M_{k}\right) \\
(\mathrm{N} \mathrm{m})\end{array}$ & $\begin{array}{c}u_{A} \\
(\mathrm{~N} \mathrm{~m})\end{array}$ \\
\hline 1 & 7 & 354.2 & 166.7 & 29.39 & 9.3 \\
\hline 2 & 10 & 506 & 262.2 & 42.39 & 13.41 \\
\hline 3 & 12 & 607.2 & 299.9 & 64.51 & 20.4 \\
\hline 4 & 15 & 759 & 389.1 & 62.23 & 19.68 \\
\hline 5 & 18 & 910.8 & 460.1 & 82.61 & 26.12 \\
\hline
\end{tabular}

TABLE 1. Estimation of measured values and their uncertainty calculated using an A-type method.

$u_{C}=u_{A}=9.3 \mathrm{Nm}$, and coefficient $k=2.26$ based on the distribution $t$ for $v=9$ degrees of freedom, and this coefficient defines the interval with an estimated confidence level of $95 \%$. The same record can also be introduced for other values of $\overline{M_{k i}}$, where $i=1,2, \ldots, k(k=5)$.

Figures 3 and 4 show the relation of the measured values of torque $M_{k}$ to the surface area of the sample material $S_{m}$. In order to describe this relation mathematically, the multi-nominal third degree approximation is applied. Setting the estimation of the multi-nominal coefficients through a least squares method, as seen from the function, units with square and cube values are small:

$$
y=-103.19+0.9447 x-(0.02449 x)^{2}+(0.00669 x)^{3} .
$$

In the same way, we can describe the second degree multi-nominal (Fig. 3) and also linear approximation (Fig. 4).

Supposing that the mathematical formula for the calculating force has the form $[3,4]$

$$
F=\tau S_{m}
$$

the linear function can be used, so formula (1) can be rewritten to express the torque

$$
M_{k}=\tau R S_{m}
$$




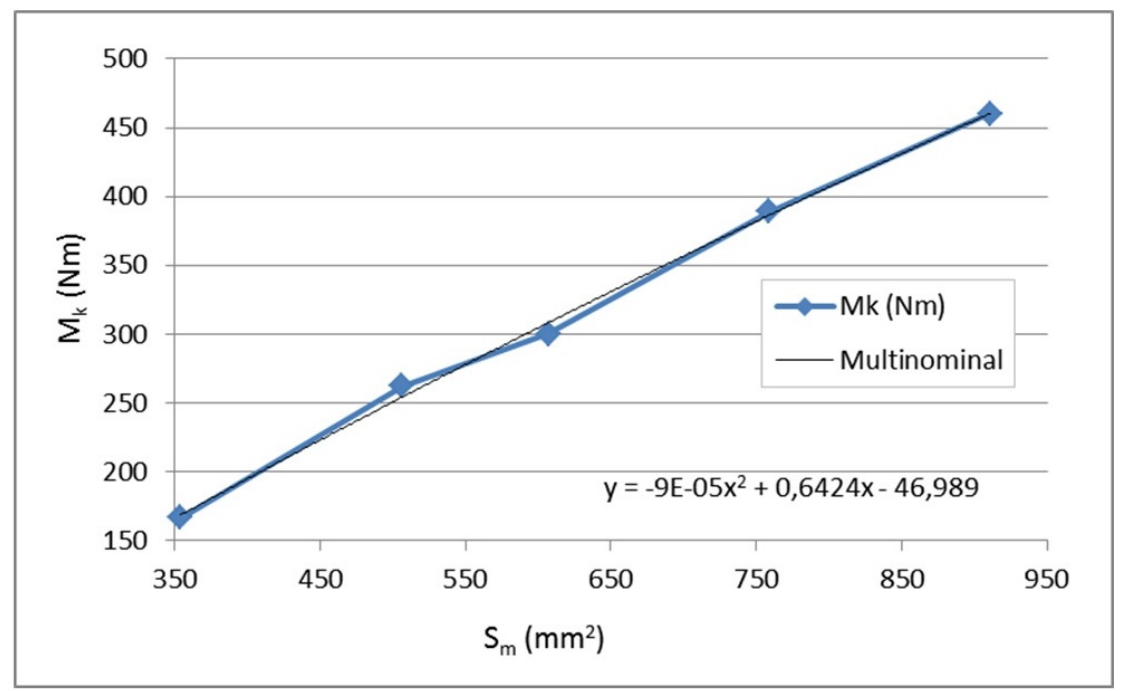

FIGURE 3. Relation of the torque to the disintegrating surface area of the material sample cross-section of the material sample, with second degree multi-nominal approximation.

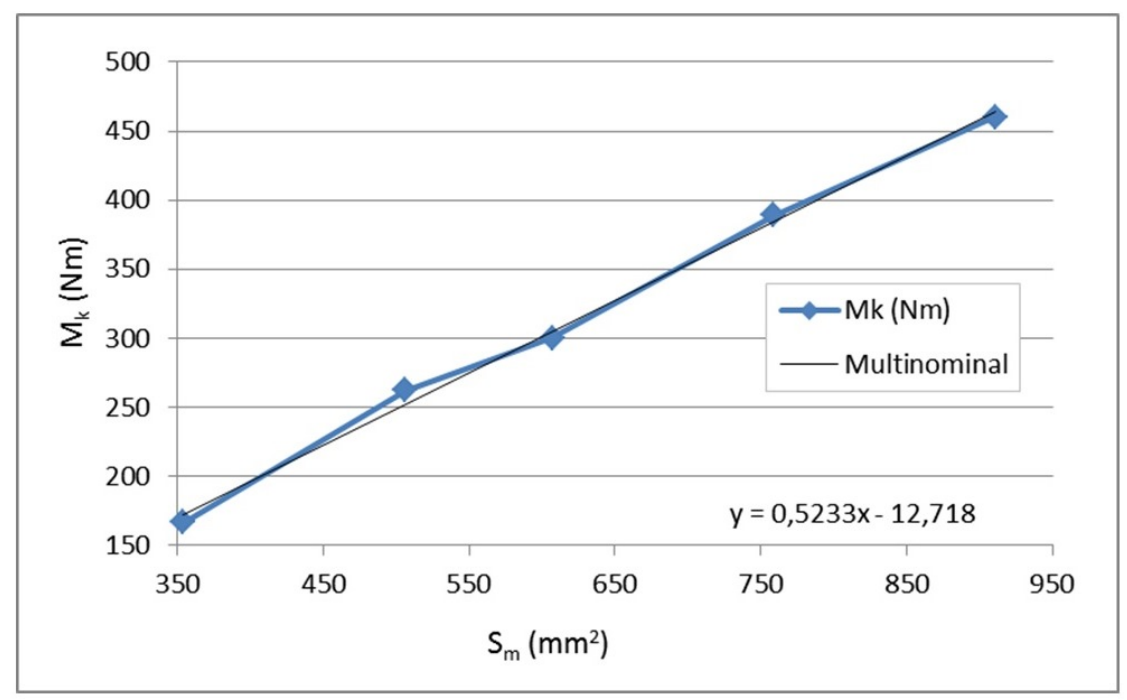

FIGURE 4. Relationship of the torque to the disintegrated surface area of the cross-section of the material sample, with a linear approximation function.

The relation between force $F$ and torque $M_{k}$ is directly proportional, so only the linear dependencies are considered, which are shown in Fig. 4.

The linear approximation function that describes the relation of the torque to the disintegrating surface area of the material cross-section is

$$
M_{k}=0.5235 S_{m}-12.897 .
$$

Formulas (1) and (3) are similar, and therefore the presumption expressing the relation between the material shearing strength $\tau$ and the disintegrating surface area of the material cross-section $S_{m}$ is correct. From a physical point of view, when the disintegrating surface area of the cross-section of the material is zero, the torque is also zero. Therefore the mathematical model is not third degree multi-nominal, and it is also not linearly dependent $y=a+c x$, but only the expression $y=c x$ is used. On the basis of this assumption, formula (1) is suitable for describing the load during the disintegration process 5 .

For various surface areas of the cross-sections, the following torque measurements were taken $[6,7,8]$ :

- $M_{k 1,1}, M_{k 1,2}, \ldots, M_{k 1,10}$ for $S_{m 1}$;

- $M_{k 2,1}, M_{k 2,2}, \ldots, M_{k 2,10}$ for $S_{m 2}$;

:

- $M_{k 5,1}, M_{k 5,2}, \ldots, M_{k 5,10}$ for $S_{m 5}$.

An estimation of the torque moment value for a given surface area of the cross-section of the material sample was calculated as the arithmetic mean of the correspondingly measured torques for each $S_{m l}, l=$ $1, \ldots, 5$ :

$$
\overline{M_{k l}}=\frac{1}{n} \sum_{j=1}^{n} M_{k l, j} .
$$

The functional dependence of the torques $M_{k}$ on 


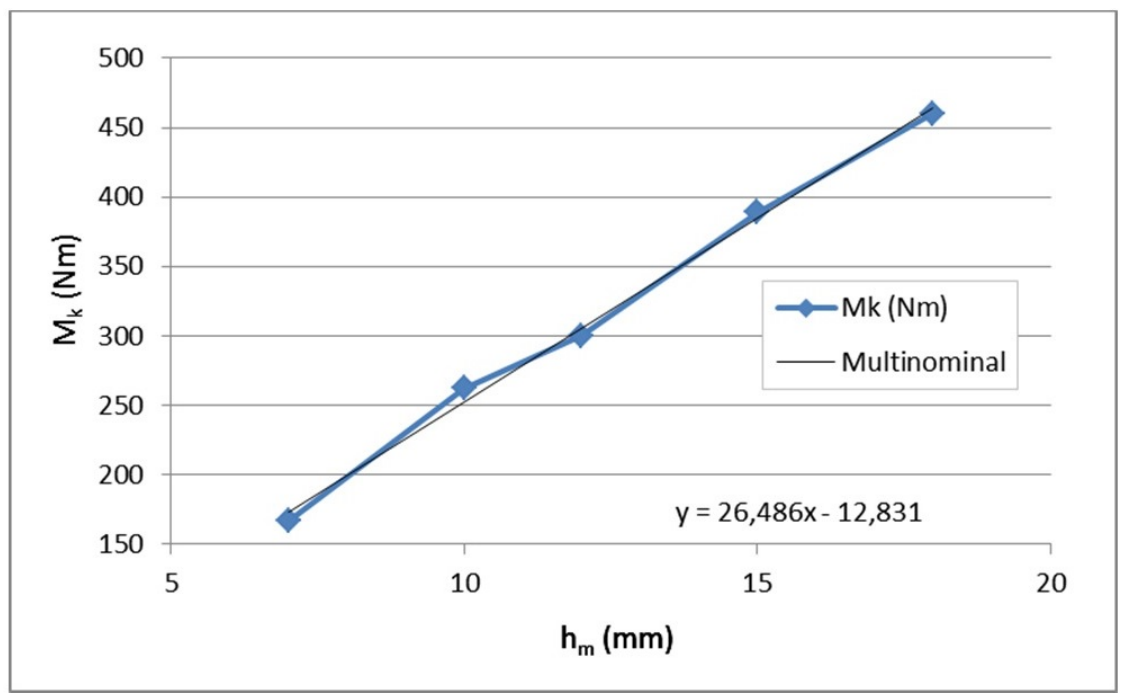

Figure 5. Relationship of the torque to the thickness of the material sample with a linear approximation function.

the surface area of a cross-section $S_{m}$ can be written as

$$
M_{k}=c S_{m}
$$

Mathematical model for single units

$$
\overline{M_{k l}}=c S_{m l}, \quad l=1, \ldots, 5
$$

can be written in matrix notation as

$$
\boldsymbol{X}=\boldsymbol{A a},
$$

where $\boldsymbol{X}$ is the matrix of input data, $\boldsymbol{A}$ is the known matrix of the measurement plan, and $\boldsymbol{a}$ is the vector of unknown parameters, given by

$$
\boldsymbol{X}=\left(\begin{array}{c}
\overline{M_{k 1}} \\
\overline{M_{k 2}} \\
\vdots \\
\overline{M_{k 5}}
\end{array}\right), \quad \boldsymbol{a}=[c], \quad \boldsymbol{A}=\left(\begin{array}{c}
S_{m 1} \\
S_{m 2} \\
\vdots \\
S_{m 5}
\end{array}\right)
$$

It is necessary to obtain an estimation of unknown parameter $b$ and the uncertainties of this estimation. Obtaining the estimation of parameter $c$ :

$$
\hat{\boldsymbol{a}}=\left(\boldsymbol{A}^{T} \boldsymbol{U}^{-1}(\boldsymbol{x}) \boldsymbol{A}\right)^{-1} \boldsymbol{A}^{T} \boldsymbol{U}^{-1}(\boldsymbol{x}) \boldsymbol{x},
$$

where $\hat{\boldsymbol{a}}$ is the vector of the estimations of the unknown parameters, $\boldsymbol{x}$ is the vector of the estimations of the input parameters, and $\boldsymbol{U}(\boldsymbol{x})$ is the covariance matrix, which is of the form $\boldsymbol{U}(\boldsymbol{x})$

$$
=\left(\begin{array}{cccc}
u^{2}\left(M_{k 1}\right) & u\left(M_{k 1}, M_{k 2}\right) & \cdots & u\left(M_{k 1}, M_{k 5}\right) \\
u\left(M_{k 2}, M_{k 1}\right) & u^{2}\left(M_{k 2}\right) & & u\left(M_{k 2}, M_{k 5}\right) \\
\vdots & & \ddots & \vdots \\
u\left(M_{k 5}, M_{k 1}\right) & u\left(M_{k 5}, M_{k 2}\right) & \cdots & u^{2}\left(M_{k 5}\right)
\end{array}\right),
$$

where $u^{2}\left(M_{k 1}\right), \ldots, u^{2}\left(M_{k 5}\right)$ are uncertainties of the torque, calculated by the type A method (Tab. 1), since other uncertainties are neglected, and $u\left(M_{k l}, M_{k l^{\prime}}\right), l, l^{\prime}=1, \ldots, 5$, are the covariance between torques $M_{k l}$ and $M_{k l^{\prime}}$.
Due to the absence of a common influence on the measurements of torques $M_{k l}, M_{k(l+1)}$, the covariances between them can be neglected, so the covariance matrix $\boldsymbol{U}(\boldsymbol{x})$ takes the form

$$
\boldsymbol{U}(\boldsymbol{x})=\left(\begin{array}{cccc}
u^{2}\left(M_{k 1}\right) & 0 & \cdots & 0 \\
0 & u^{2}\left(M_{k 2}\right) & & 0 \\
\vdots & & \ddots & \vdots \\
0 & 0 & \cdots & u^{2}\left(M_{k 5}\right)
\end{array}\right) .
$$

The matrix of the estimation of the unknown parameter can be calculated as

$$
\boldsymbol{U}(\hat{\boldsymbol{a}})=\left(\boldsymbol{A}^{T} \boldsymbol{U}^{-1}(\boldsymbol{x}) \boldsymbol{A}\right)^{-1},
$$

where matrix $\boldsymbol{U}(\hat{\boldsymbol{a}})$ is a single variable matrix

$$
\boldsymbol{U}(\hat{\boldsymbol{a}})=\left[u^{2}(c)\right]
$$

where $u(c)$ is the uncertainty of the unknown parameter $c$.

\section{Conclusion}

By calculating matrix relations (5) and $(6)$ we obtain the parameter $c=0.5$ and uncertainty $u(c)=0.013$. Therefore,

$$
M_{k}=0.5005 S_{m}
$$

Considering practical values of $c=0.5 \mathrm{kN} \mathrm{mm}^{-1}$ and $u(c)=0.013 \mathrm{kN} \mathrm{mm}$, the uncertainty of the calculated torque $M_{k}$ by formula (4) is found to be

$$
u\left(M_{k}\right)=u(c) S_{m}
$$

Comparing formulas (7) and (2), the tensile shear strength $\tau$ of the disintegrating material is $c / R(R=$ $0.1165 \mathrm{~m}$ ), thus $\tau=4.29 \mathrm{MPa}$. The table value of tensile shear strength $\tau$ is found by [4] to be $\tau_{\text {tab }}=$ 6.7 MPa.

Based on earlier experiments and from the fact that the $c / R$ ratio is not equal to the shear strength $\tau$, 
it can be hypothesized that formulas (7) must also reflect an additional parameter $\gamma$. Therefore it is necessary to perform further experiments, where the influence of the cutting-edge side rake $\gamma$ on the torque moment $M_{k}$ will be monitored, as well as adding a new coefficient to the formula that will reflect the influence of this parameter.

The same relation as is illustrated in Fig. 3 and Fig. 4 can be made for the thickness of the material sample $h_{m}$, and the character of the torque on different thicknesses of the material sample is shown in Fig. 5

\section{REFERENCES}

[1] Lisý, M., Baláš, M., Moskalík, J., Štelcl, O., Biomass gasification - primary methods for eliminating tar, (2012) Acta Polytechnica, 52 (3), pp. 66-70.

[2] Moskalík, J., Škvařil, J., Štelcl, O., Baláš, M., Lisý, M.: Energy recovery from contaminated biomass, (2012) Acta Polytechnica, 52 (3), pp. 77-82.
[3] Kováč, A., Rudolf, B. Tvárniace stroje, SNTL, Alfa, Bratislava 1989.

[4] Lisičan, J. Teória a technika spracovania dreva. Matcentrum, Zvolen 1996.

[5] Beniak, J., Ondruška, J., Čačko, V.: Design process of energy effective shredding machines for biomass treatment. Acta Polytechnica 52 (5), 2012, pp. 133-137.

[6] Palenčár, R., Halaj, M. Metrologické zabezpečenie systémov riadenia kvality, Vydavatelstvo STU v Bratislave 1998, ISBN 80-227-1171-3.

[7] Palenčár, R., Ruit, J.-M., Janiga, I., Horníková, A. Štatistické metódy v metrologických a skúšobných laboratóriách, Grafické štúdio Ing. Peter Juriga, 2001,ISBN 80-968449-3-8.

[8] Jarošová, E. Navrhování experimentů. Česká společnost pro jakost, 1997. 